\title{
Differential Maturation of Climbing Fiber Innervation in Cerebellar Vermis
}

\author{
Hiroshi Nishiyama and David J. Linden \\ Department of Neuroscience, The Johns Hopkins University School of Medicine, Baltimore, Maryland 21205
}

\begin{abstract}
Folding of the brain surface is a general morphological adaptation to maximize surface area in a limited cranial volume. Surface folding is present not only in the neocortex but also in the cerebellar cortex. This folding creates subdivisions of the cortical surface: the sulci, the gyri, and the straight bank region, which is interposed. Is cortical folding only the solution to a surface-volume problem or does it also confer functional differences on the subdivisions that are created by this geometry? Here we have used the innervation of Purkinje cells by climbing fibers as a model system to explore potential functional differences. Purkinje cells are innervated by multiple climbing fibers at birth but undergo an activity-dependent refinement, such that by postnatal day (P) 21, most are contacted by a single climbing fiber. Using whole-cell recording from slices of cerebellar vermis derived from juvenile (P18-25) or adult (P60-83) mice, we found that significantly more Purkinje cells in the sulcus were innervated by multiple climbing fibers than in the gyrus or bank subdivisions; however, the basic properties of climbing fiber-Purkinje cell EPSCs such as kinetics, amplitude, and paired-pulse ratio were similar across cortical subdivisions. To search for a morphological correlate of differential multiple climbing fiber innervation, we labeled climbing fibers and performed reconstructions of immunofluorescent images. These revealed that, unlike the bank-gyrus subdivisions, most of the climbing fibers in the sulcus do not innervate the superficial molecular layer. These findings suggest that the subdivisions of the cerebellar cortex produced by folding may create functionally distinct entities.
\end{abstract}

Key words: multiple innervation; Purkinje cell; surface folding; dendrite; bank; sulcus

\section{Introduction}

Folding of the cortical surface is a solution to the problem of packing a large surface area into a small volume that may be seen in both the neocortex of higher mammals and the cerebellar cortex of a wide range of vertebrates. The features that emerge from this folding, the sulci, gyri, and interposed straight bank region, have been characterized anatomically (Braitenberg and Atwood, 1958; Eccles et al., 1967; Welker, 1990; Herrup and Kuemerle, 1997), but the functional correlates of these subdivisions have received little attention. The cerebellar cortex is a particularly useful model system in this endeavor. The cerebellum is composed of a relatively small number of cell types arranged in a highly stereotypic manner, and their interconnections have been extensively characterized.

Previous anatomical work has described several important differences in the structure of these subdivisions. The granule cell layer is thickest where it underlies the gyri, is diminished in the bank region, and is thinner still in the sulci. A similar gradient may be seen in Purkinje cell (PC) density (Braitenberg and Atwood, 1958). Perhaps most interesting is a systematic variation in

Received Dec. 19, 2003; revised Feb. 25, 2004; accepted March 15, 2004.

This work was supported by National Institute of Mental Health Grants MH51106 and MH01590 and the Develbiss Fund (D.J.L.). We thank R. Bock for skillful assistance and S. J. Kim, A. Sdrulla, J. H. Shin, and W. Zhang for helpful comments on this manuscript.

Correspondence should be addressed to David J. Linden, Department of Neuroscience, The Johns Hopkins University School of Medicine, 725 North Wolfe Street, Baltimore, MD 21205. E-mail: dlinden@jhmi.edu.

D0I:10.1523/JNEUROSCI.5610-03.2004

Copyright $\odot 2004$ Society for Neuroscience $\quad$ 0270-6474/04/243926-07\$15.00/0 dendritic morphology such that the primary dendrite of gyrus or bank Purkinje cells ascends for tens of micrometers before dividing at a relatively narrow angle, whereas the primary dendrite of sulcus Purkinje cells branches almost immediately and does so at a wider angle (Eccles et al., 1967).

Typically, the dendrite of the Purkinje cell is elaborated in a single parasagittal plane. Purkinje cells receive excitatory glutamatergic drive from two inputs that are organized quite differently. Each Purkinje cell receives $\sim 100,000$ synapses (in the mouse) from small unmyelinated parallel fibers that are the axons of cerebellar granule cells and run normal to the plane of the Purkinje cell dendrite (Kurihara et al., 1997). In marked contrast, each Purkinje cell is said to be innervated by a single climbing fiber (CF) axon, originating in the inferior olive, and elaborating $\sim 1400$ release sites (Strata and Rossi, 1998) (measured in the rat). Although each Purkinje cell is multiply-innervated at birth, an activity-dependent regression of supernumerary CFs proceeds, yielding single innervation for most Purkinje cells by postnatal day (P) 21 (Crépel et al., 1976; Lohof et al., 1996). A wide variety of naturally occurring and induced mutations in mice can result in persistent multiple CF innervation that is often accompanied by ataxia (Crépel and Mariani, 1976; Mariani et al., 1977; Mariani and Changeux, 1980; Kano et al., 1995; Kano et al., 1997, 1998; Levenes et al., 1997; Offermanns et al., 1997; Hashimoto et al., 2001; Ichikawa et al., 2002).

The small number of CFs innervating Purkinje cells and their remarkable maturation pattern make this an ideal model system to search for physiological correlates of folding-induced cortical 
subdivisions. Here we have recorded climbing fiber-evoked EPSCs and reconstructed climbing fiber morphology in an attempt to uncover these correlates.

\section{Materials and Methods}

CF EPSC recording. Parasagittal slices of cerebellar vermis and parasagittal or coronal slices of cerebellar hemisphere $(200 \mu \mathrm{m}$ thick) were prepared from $\mathrm{P} 18-83$ mice $(\mathrm{F} 1$ hybrid of $\mathrm{C} 57 \mathrm{BL} / 6 \times \mathrm{C} 3 \mathrm{H}$ mice) using a vibrating tissue slicer and ice-cold artificial CSF (ACSF) containing (in m): $124 \mathrm{NaCl}, 2.5 \mathrm{KCl}, 2.5 \mathrm{CaCl}_{2}, 1.3 \mathrm{MgCl}_{2}, 1 \mathrm{NaH}_{2} \mathrm{PO}_{4}, 26.2$ $\mathrm{NaHCO}_{3}$, and 15 glucose bubbled with $95 \% \mathrm{O}_{2}$ and $5 \% \mathrm{CO}_{2}$. After a recovery period of at least $1 \mathrm{hr}$, the slices were placed in a submerged chamber that was perfused with ACSF supplemented with $5 \mu \mathrm{M}$ Gabazine to block $\mathrm{GABA}_{\mathrm{A}}$ receptors. The patch electrodes were filled with a solution containing (in mM): 135 Cs-methanesulfonate, $10 \mathrm{CsCl}, 10 \mathrm{HEPES}$, 0.2 EGTA, $4 \mathrm{Na}_{2}$-ATP, 0.4 Na-GTP, pH 7.3 adjusted with CsOH. Wholecell voltage-clamp recordings were performed from visually identified Purkinje cells at room temperature. CFs were stimulated by applying paired-pulses (amplitude, 10-30 $\mu \mathrm{A}$; interval, $100 \mathrm{msec}$ ) through a glass pipette (2-3 $\mu \mathrm{m}$ tip diameter) filled with ACSF. To search for multiple $\mathrm{CF}$ innervation, we systematically moved the stimulation pipette in the granule cell layer, and the stimulus pulse width was gradually increased over the range of $20-2000 \mu \mathrm{sec}$ at each stimulation site. Because pulse width can be controlled with a digital stimulator, accurate and reproducible control of stimulus intensity was accomplished (in contrast to pulse amplitude, which is set by an analog potentiometer). CF-PC EPSCs were identified by their all-or-none response and paired-pulse depression (PPD).

Anterograde labeling and immunohistochemistry. This procedure has been modified from that of Kreitzer et al. (2000). Sprague Dawley rats (P18-22) were anesthetized with an intraperitoneal injection of ketamine $(110 \mathrm{mg} / \mathrm{kg})$ and xylazine $(10 \mathrm{mg} / \mathrm{kg})$ and placed in a stereotaxic device. The muscles and overlying fascia were pulled aside to expose the dura between the foramen magnum and C1. A glass pipette with 40-50 $\mu \mathrm{m}$ tip diameter was filled with mineral oil and connected to a Hamilton syringe. The tip of the glass pipette was then front filled with $\sim 0.5 \mu \mathrm{l}$ of Alexa Fluor 488 or 546 dextran-conjugate dissolved in PBS at a concentration of $10 \%$. Injections were made unilaterally at the midline, just rostral to the dorsomedian spinal vein at a depth of $2.2-2.5 \mathrm{~mm}$. The pipettes were at an angle of $54^{\circ}$ from vertical and $5^{\circ}$ from the midline. A dye volume of $0.2-0.3 \mu \mathrm{l}$ was delivered over $15 \mathrm{~min}$ with a syringe pump. The pipettes were then left in place for $10 \mathrm{~min}$ before they were withdrawn.

After a survival period of 3-5 d, animals were perfused intracardially with $4 \%$ paraformaldehyde in PBS, $\mathrm{pH} 7.4$, at $4^{\circ} \mathrm{C}$. The cerebellum was then removed and postfixed in the same fixative for $24 \mathrm{hr}$ at $4^{\circ} \mathrm{C}$. Parasagittal slices $(80 \mu \mathrm{m}$ thick) of cerebellar vermis were incubated with rabbit anti-Alexa 488 polyclonal antibody $(\mathrm{Ab})$ and mouse anticalbindin-D-28K monoclonal Ab. The slices were then incubated with the secondary antibodies: Alexa 488-labeled goat anti-rabbit Ab and Alexa 546-labeled goat anti-mouse $\mathrm{Ab}$. The images were acquired using a laserscanning confocal microscope (Zeiss LSM 510).

Quantification of CF innervation. Quantitative image analysis was performed using Image J software. The cerebellar molecular layer was divided into four segments (see Fig. 5), and the number of green (climbing fiber-labeled) pixels for which the fluorescent intensity was above the threshold was counted in each segment. Care was taken to define the analysis regions such that no suprathreshold green pixels were excluded. The threshold was set to $2 \times$ background green fluorescent intensity. The number of pixels above the threshold in each segment (representing the size of CF innervation in a given segment) was then divided by the total number of suprathreshold pixels in all four segments (representing the size of total CF innervation). The resultant ratio is a measure of the degree of CF innervation in each segment.

\section{Results}

Visualized whole-cell patch-clamp recordings were made from the somata of Purkinje cells in parasagittal slices prepared from
A

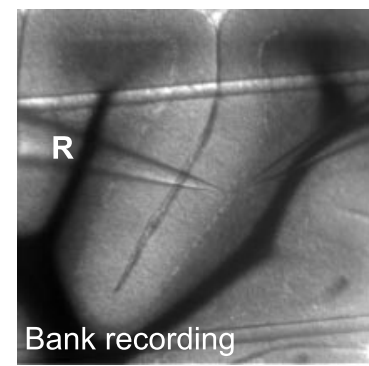

C
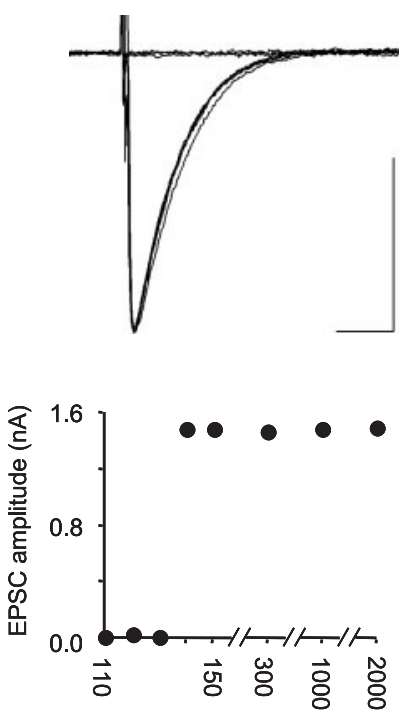

Stimulus pulse width ( $\mu \mathrm{sec})$
B

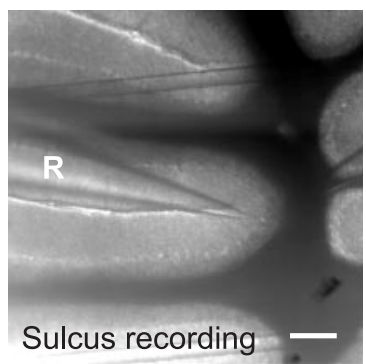

D

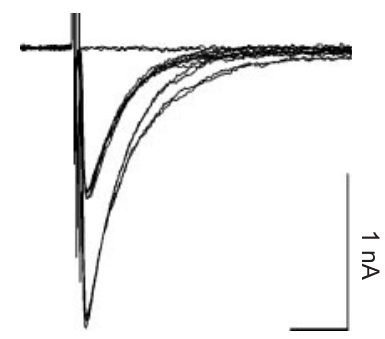

$20 \mathrm{msec}$

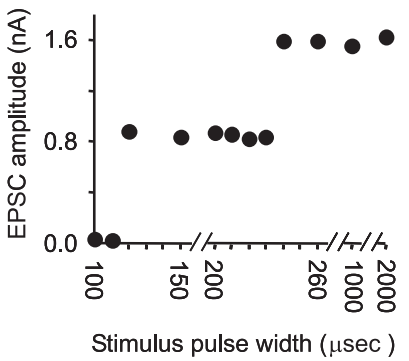

Figure 1. Whole-cell patch-clamp recordings from Purkinje cells reveal $C F$ multiple innervation. CF-PC EPSCs were evoked by a stimulation pipette placed in the granule cell layer. $A, B$, Examples of the location of recorded Purkinje cells in bank $(A)$ and in sulcus $(B)$ are shown in images from transilluminated parasagittal slices. The recording pipette is indicated by " $\mathrm{R}$ " in each figure. Scale bar, $200 \mu \mathrm{m}$. C, D, Representative traces of CF-PC EPSCs innervated by single $(C)$ and double $(D) C F s$, and corresponding plot of EPSC peak amplitude as a function of stimulus intensity. Holding potential was $-18 \mathrm{mV}$.

mouse cerebellar vermis. The slices were bathed in standard ACSF supplemented with $5 \mu \mathrm{M}$ Gabazine to block $\mathrm{GABA}_{\mathrm{A}}$ receptors. For recording electrode placement, we divided the folia into three regions-the top of the folia (gyrus), straight segment (bank), and the base of the folia (sulcus)—and recorded from identified Purkinje cells (Fig. 1 $A, B$ ). Stimulating electrodes were placed in the underlying granule cell layer and CF EPSCs were recorded in voltage-clamp mode at a holding potential of -20 to $-10 \mathrm{mV}$ to inactivate voltage-gated channels and reduce AMPA receptor driving force, thereby improving voltage-clamp quality. We used pairs of stimuli (interval, $100 \mathrm{msec}$ ) to distinguish CF EPSCs (which show PPD) from EPSCs mediated by parallel fiber activation (which show paired-pulse facilitation). At each stimulation site, the amplitude of the current pulse $(10-30 \mu \mathrm{A})$ was fixed, and the pulse width was gradually increased over the range of 20-2000 $\mu \mathrm{sec}$. In most PCs, large EPSCs were elicited in an all-or-none manner as the stimulus intensity was gradually increased, which indicated single innervation (Fig. 1C). In some PCs, a second or third discrete current step appeared as the stimulus intensity was increased further, indicating multiple innervation (Kano et al., 1995) (Fig. 1D). 

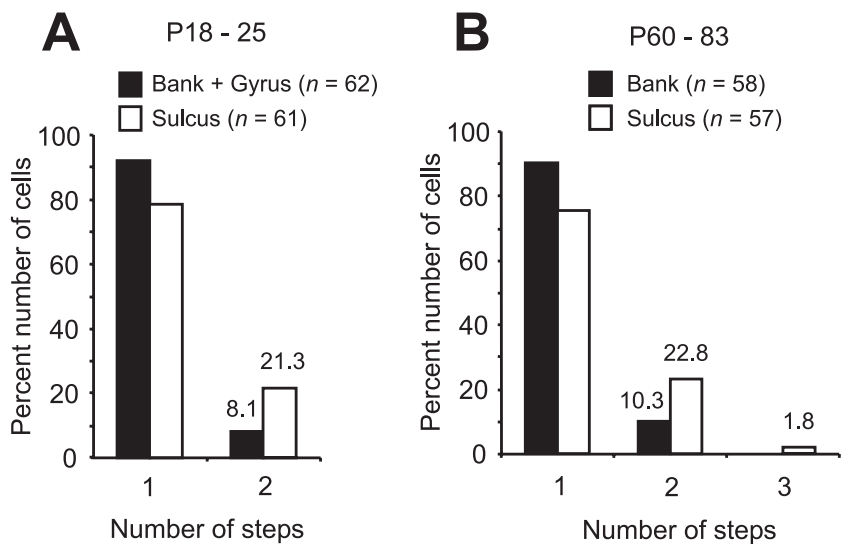

Figure 2. The proportion of Purkinje cells innervated by multiple CFs is greater in the sulcus subdivision than the bank subdivision in the cerebellar vermis. Percentage of Purkinje cells showing number of discrete steps of CF-PC EPSC in bank (closed column) and in sulcus (open column) in the cerebellar vermis. Data in $A$ and $B$ were obtained from parasagittal slices of juvenile mice (P18-25; 123 cells from 21 animals) and adult mice ( $P 60$ - 83; 115 cells from 19 animals), respectively. Numbers above the bars indicate percentage of Purkinje cells showing multiple CF innervation.

Using mice at ages P18-25, we found that $8.1 \%$ of PCs in the bank and gyrus regions $(n=62)$ showed CF multiple innervation. In contrast, $21.3 \%$ of PCs in the sulcus regions $(n=61)$ were innervated by multiple CFs. The frequency distribution of PCs in terms of the number of discrete EPSC steps showed a significant difference between the sulcus and other regions $\left(p<0.05 ; \chi^{2}\right.$ test) (Fig. $2 A$ ). Subsequent experiments with a new population of PCs were designed to specifically compare the gyrus with the bank region. These showed no statistically significant difference: $9.8 \%$ of PCs in the bank $(n=41)$ and $12.2 \%$ of PCs in the gyrus $(n=41)$ were innervated by multiple CFs.

To examine whether the developmental regression of multiple $\mathrm{CFs}$ is delayed in the sulcus, we repeated this experiment using adult mice (P60-83) (Fig. 2B). Even in mice at this age, $24.6 \%$ of PCs in the sulcus $(n=57)$ remained innervated by multiple CFs (one of those PCs was triple innervated) in contrast to $10.3 \%$ of multiply-innervated PCs in the bank $(n=58)$. The difference between these two regions was statistically significant $(p<0.05$; $\chi^{2}$ test). Although the numbers of PCs that we recorded in any single lobule was low, there was no obvious lobule preference for distribution of multiply-innervated PCs (data not shown). These results indicate that multiply-innervated PCs reside preferentially in the sulcus and that this does not represent a developmental delay of this region but rather is a persistent difference in circuit connectivity.

Developmental regression of multiple CFs may be determined in part by the properties of CF-Purkinje cell synaptic drive. We therefore measured several electrophysiological parameters of CF EPSCs recorded from adult mice. Purkinje cells were divided into two groups: those innervated by a single CF and those innervated by two CFs. In the latter group, only the first discrete EPSC step was analyzed. Measurement of the amplitude, $10-90 \%$ rise time, and 50\% decay time for CF EPSCs did not reveal significant differences between the sulcus and the bank regions (Fig. $3 B$ ). We next measured PPD, which is a form of short-term plasticity observed at the CF-Purkinje cell synapse. This phenomenon appears to be mediated presynaptically (Hashimoto and Kano, 1998; Silver et al., 1998). Andjus et al. (2003) have shown that increasing the firing rate of CFs during the P9-12 period (through systemic administration of the drug harmaline) results
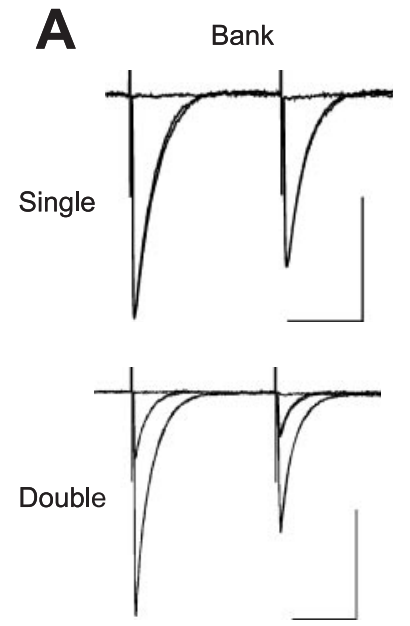

B
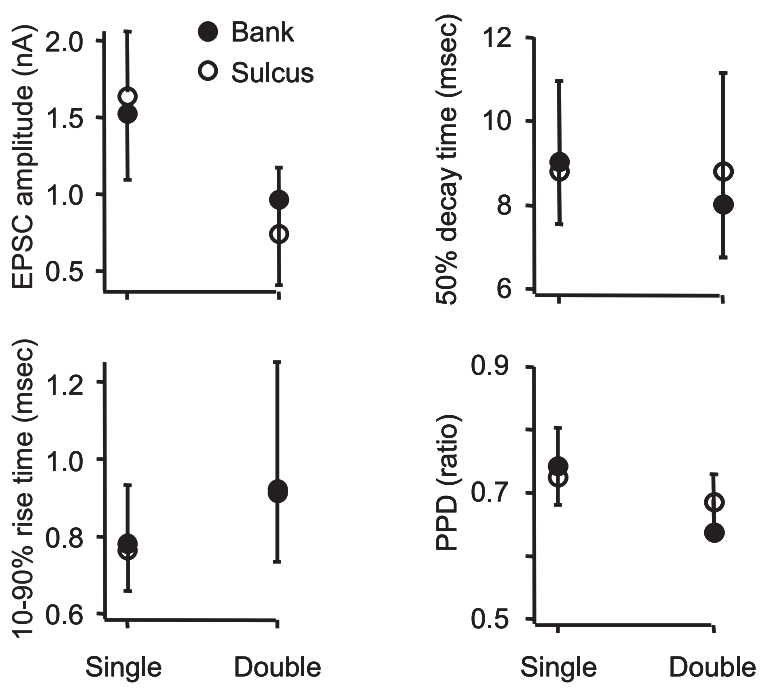

Figure 3. Amplitude, paired-pulse depression, and kinetics of CF EPSCs are not different between bank and sulcus Purkinje cells. $A$, Representative traces showing single and double CF innervation recorded from Purkinje cells in bank and in sulcus in the cerebellar vermis of adult mice. Several traces at subthreshold and suprathreshold stimulus intensity are superimposed. $B$, Electrophysiological parameters of the CF EPSP in bank (closed circle; $n=38$ for single innervation and $n=6$ for double innervation) and in sulcus (open circle; $n=35$ for single innervation and $n=12$ for double innervation). Measurements for double-innervated cells were made using the lower threshold CF response. Averaged holding potential was $-17.0 \pm$ $3.1 \mathrm{mV}$ in bank and $-17.2 \pm 3.1 \mathrm{mV}$ in sulcus (mean $\pm \mathrm{SD}$ ). Data in the figure are represented as the mean \pm SD.

in persistent multiple CF innervation accompanied by enhanced PPD in rats (Andjus et al., 2003). Thus we examined whether greater CF multiple innervation in the sulcus subdivision was also accompanied by enhanced PPD. As shown in Figure 3B, however, there was no significant difference in PPD between sulcus and bank CFs. These results indicate that postsynaptic responses in Purkinje cells and presynaptic functions of CF terminals are similar in these two subdivisions.

Does the persistent difference in circuit connectivity between the sulcus and the bank regions (assessed electrophysiologically as multiple CF innervation) correlate with some difference in the CF innervation pattern? We have begun to address this point through double labeling of CFs and PCs. This experiment was done using rats (P18-22 at the day of injection) because we found a similar result in terms of differential multiple CF innervation: $15 \%$ of PCs were multiply-innervated in the sulcus $(n=20)$ 
Bank
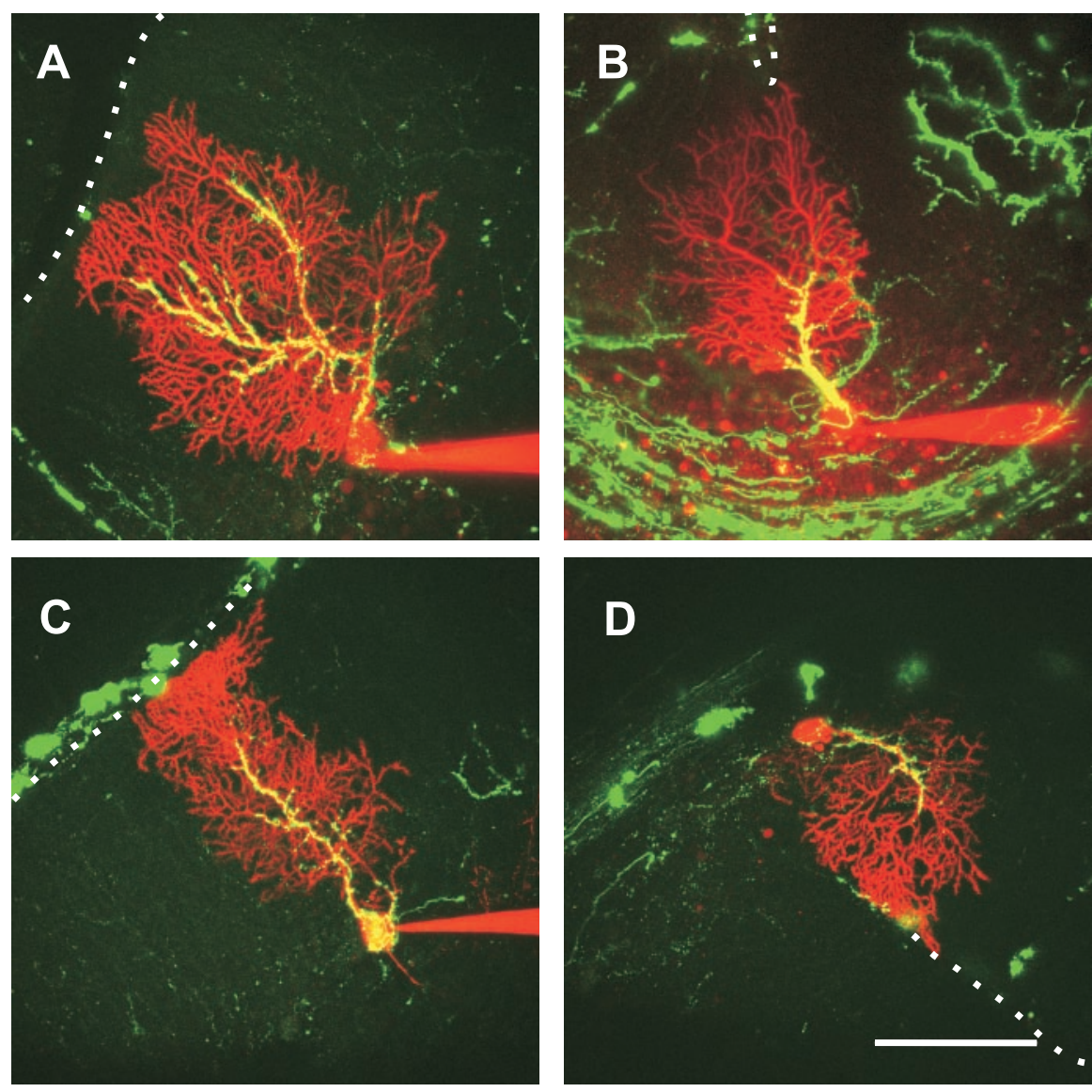

Figure 4. Difference in CF innervation pattern between bank and sulcus. CFs were labeled with dextran-conjugated green fluorescent tracer injected into the inferior olive in rats. Purkinje cells innervated by the labeled CFs were identified in living brain slices using a microscope equipped with both fluorescence and infrared gradient contrast optics and then labeled with a red fluorescent dye via a patch pipette. Projected confocal stacks show that $C F$ s in sulcus $(B, D)$ are restricted to more proximal portions of the dendritic tree of the target Purkinje cells than those in bank $(A, C)$. Note that the relatively thick secondary dendritic branches of target Purkinje cells were not innervated by the CF in $B$. White dotted lines indicate the pial surface. Scale bar, $100 \mu \mathrm{m}$. apexes are on the Purkinje cell layer) and then subdivided into four polygonal segments of the same thickness (Fig. 5B). At first glance, unequal area size of four polygonal segments may appear to distort the measurement in the sulcus regions; however, our quantification method is not affected by the area size of each segment. We made sure that all of the pixels representing the CF signal were included in one of the four segments, and then we scored the segments using the number of CF pixels in a given segment divided by the total number of CF pixels (not a mean pixel value that would be affected by the segment area). As shown in Figure $5 C$, the $\mathrm{CF}$ innervation field in the sulcus regions was significantly closer to the Purkinje cell layer than that in the bank regions. In the bank, $45.7 \pm 3.0 \%$ of the total CF innervation field was found in the most proximal segment (segment 1), whereas in the sulcus this figure was $64.2 \pm 4.6 \%(p<0.01$; Student's $t$ test). This pattern was reversed in more distal analysis segments 2 and 3 , in which the degree of CF innervation was significantly higher in bank than sulcus ( $p<0.05$ for each). Importantly, this measure was not confounded by a systematic difference in the thickness of the molecular layer between bank and sulcus regions (bank: $190.2 \pm 5.9 \mu \mathrm{m}$; sulcus: $193.2 \pm 4.2 \mu \mathrm{m})$ (Fig. 5C, inset). Although the population of CFs is significantly more restricted to proximal portions of the molecular layer in sulcus than bank (Fig. 6C), a small number of atypical fibers are in both regions: bank CFs, which are proximally restricted, and sulcus $\mathrm{CFs}$, which innervate distal regions (Fig. $6 A, B$ ).

Is the difference in multiple innervation between bank and sulcus observed in the cerebellar vermis also found in the cerebellar hemispheres? To address this point, patch-clamp recordings were made in sagittal slices prepared from juvenile (P18-25) and adult (P72-82) mouse cerebellar hemisphere (Fig. 7A,B). Although the proportion of multiply-innervated PCs tended to be greater in the sulcus than in the bank, the difference was not statistically significant. We also performed the same experiment using coronal slices from young mice (P19-25) and found a similar result: there was no statistically significant difference between the bank and the sulcus (Fig. 7C).

\section{Discussion}

The main finding of this study is that the CF innervation of Purkinje cells in the sulcus subdivision of the cerebellar vermis is different from that in the bank (and gyrus) subdivision(s). First, there is a significantly higher rate of multiple CF innervation in the sulcus that persists into adulthood. Second, CFs that innervate the sulcus are restricted to more proximal portions of the Purkinje cell dendritic arbor. Interestingly, these differences in CF innervation are not associated with changes in the kinetics, amplitude, or paired-pulse depression of CF EPSCs. These find- cus, a fan-shaped polygon was drawn to cover the entire CF (one apex is the point where the pial surface was folded and other 
A

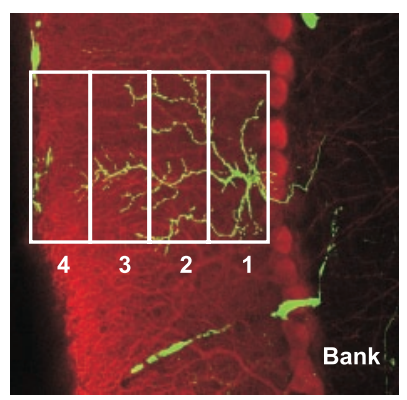

B

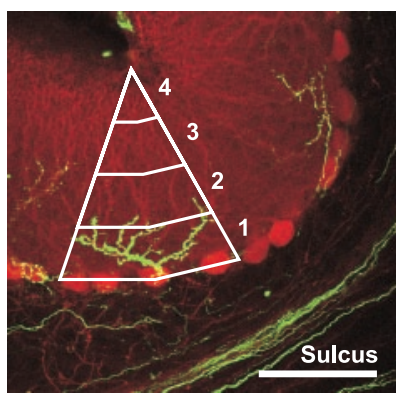

C

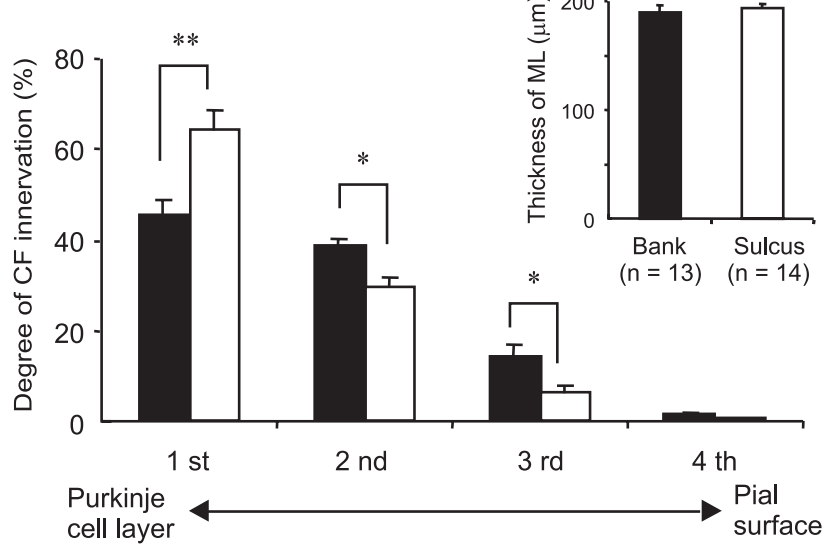

Figure 5. Most of the CFs in sulcus do not innervate the superficial portion of the molecular layer. CFs were labeled with an Ab against dextran-conjugated tracer (green), and Purkinje cells were labeled with Ab against calbindin-D-28K (red). Representative confocal stacks show the CF innervation of the molecular layer in bank $(A)$ and in sulcus $(B)$. Scale bar, $100 \mu \mathrm{m}$. For quantification, the molecular layer was divided into four segments, and the degree of $C F$ innervation in each segment was measured (see Materials and Methods). C, The degree of (F innervation in each segment in bank (closed column) and in sulcus (open column). Inset shows the thickness of molecular layer in both subdivisions. Data represent mean \pm SEM. ${ }^{*} p<0.05 ;{ }^{* *} p<0.01$.

ings suggest that the subdivisions of the cerebellar cortex produced by folding may create functionally distinct modules.

When multiple CF innervation was assessed using electrophysiological measures in cerebellar hemispheres, there was a tendency toward greater multiple CF innervation in the sulcus subdivision, but this did not reach statistical significance. It is well known that CFs in the cortex of cerebellar hemispheres are not confined strictly to parasagittal planes, as they are in the vermis (Sugihara et al., 2001). As such, it is possible that multiple innervation may be underestimated because of truncation of CFs during slice preparation. We have attempted to address this possibility by using slices cut in both parasagittal and coronal planes, both of which yielded similar results. At present, it appears that multiple climbing fiber innervation is not significantly greater in sulcus subdivisions of cerebellar hemispheres, but a small possibility remains that this analysis is obscured by the geometry of $\mathrm{CFs}$ in this region.

The highly stereotypic layer structure and local circuitry of the cerebellar cortex imply that functional partitioning is necessary for the proper functioning of the cerebellum. Previous in vivo electrophysiological studies have revealed that the cerebellar cortex is divided by its afferent circuitry into a series of bilaterally symmetric parasagittal bands along the mediolateral axis that are evolutionarily conserved (Oscarsson, 1969; Voogd, 1969; Ito, 1984). In addition, numerous molecular markers have been iden-
Atypical bank

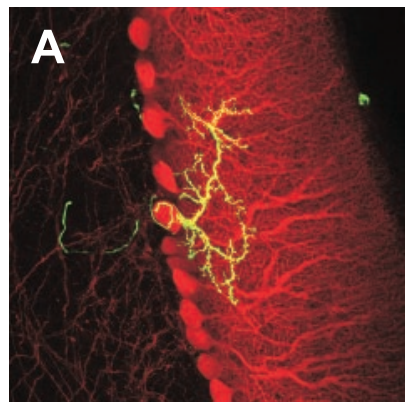

C

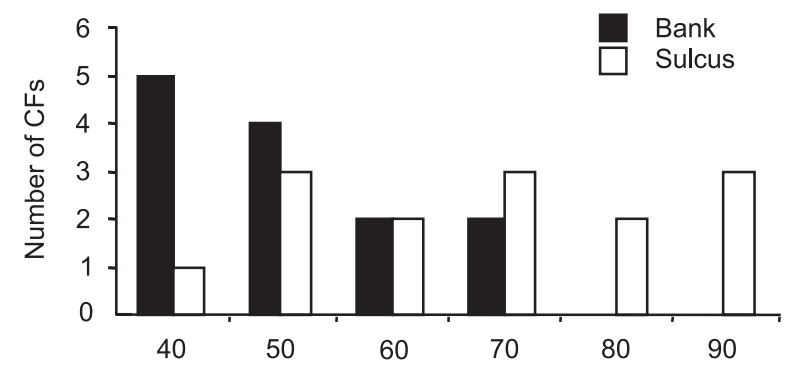

Degree of CF innervation in the 1st segment (\%)

Figure 6. Although the population of CFs is significantly more restricted to proximal portions of the molecular layer in sulcus than in bank, a small number of atypical fibers are in both regions. Examples of some atypical CF innervation patterns are shown. $A, C F$ in bank fails to innervate superficial molecular layer. $B, C$ in sulcus innervates superficial molecular layer. Scale bar, $100 \mu \mathrm{m}$. C, Histogram showing the number of CFs as a function of degree of CF innervation in the first segment.

tified that show a nearly identical parasagittally oriented zebrastripped expression pattern along the mediolateral axis (Hawkes, 1992; Hawkes and Herrup, 1995; Herrup and Kuemerle, 1997; Oberdick et al., 1998). Although less is known about the partitioning along the rostrocaudal axis, the patterns of the somatotopic map are different in different lobules (Welker, 1990). Several molecular markers have been identified that show a gradient in their expression level along the rostrocaudal axis (Herrup and Kuemerle, 1997). Thus, the cerebellar cortex is organized by biochemically and functionally distinct subdivisions along the mediolateral axis as well as the rostrocaudal axis. Our findings suggest that the sulcus in the cerebellar vermis is a novel subdivision along the rostrocaudal axis, with both anatomically and physiologically distinct properties.

Are the two differences seen herein, the greater degree of multiple CF innervation and the proximal restriction of CFs observed in the sulcus subdivision, causally related, or do they both follow independently from some underlying factor? One possibility is that both of these alterations are consequences of the thinner layer of granule cells that underlies the sulcus subdivision. Interestingly, previous work using rats treated in the early postnatal period with the antimitotic drug methylazoxymethanol acetate (which results in a generalized thinning of the cerebellar granular layer) showed a greater degree of multiple CF innervation. Furthermore, in this model of hypogranular cerebellum, CF innervation of Purkinje cells was restricted to a portion of the dendritic arbor, favoring large-caliber proximal dendrites (Bravin et al., 1995; Zagrebelsky and Rossi, 1999). Thus, it is possible that thinner layer of granule cells underlying the sulcus region results in weaker PF input to sulcus PCs, which eventually cause a greater 
A

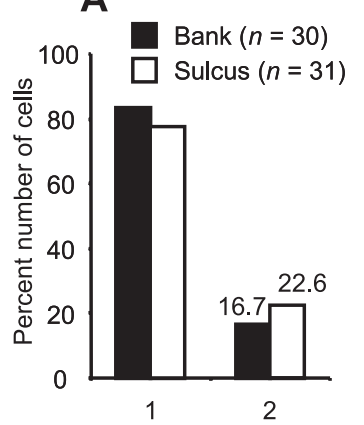

Number of steps

Sagittal, P18-25
B

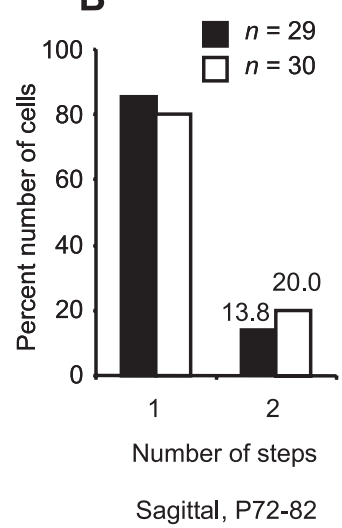

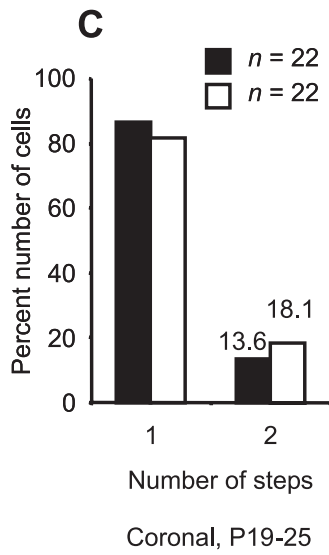

ever, that multiple climbing fiber innervation in the sulcus performs a useful integrative function. The total charge transfer from coactivation of multiple climbing fibers is usually similar to that produced by one CF in a singly innervated Purkinje cell (Kano et al., 1995, 1997, 1998; Offermanns et al., 1997) (Fig. 3A); however, the informational content conveyed by multiple $\mathrm{CF}$ innervation may be quite different. There are somatotopic maps in the cells of origin of the CFs in the inferior olive, so adjacent olivary cells convey sensorimotor information from nearby locations in the periphery (Gellman et al., 1983). Single olivary cell axons each give rise to approximately seven terminal branches (in the rat) that are called climbing fibers, and adjacent olivary cells tend to project to longitudinal bands, but in a patchy distribution (Schild, 1970; Sugihara et al.,

degree of multiple innervation and proximal restriction of CFs. It is also possible that multiple innervation and proximal restriction of CFs result from the decreased Purkinje cell density or the altered dendritic morphology found in sulcus Purkinje cells. In particular, the shorter proximal dendritic stub and wider branching angle of sulcus Purkinje cells result in a higher proportion of large-caliber dendrites in the most proximal segment of the molecular layer.

The proximal restriction of CFs in sulcus may contribute in some manner to the failure of the CF maturational process, resulting in greater multiple innervation. Perhaps the "winning" $\mathrm{CF}$ in the competition for mono-innervation is that which can produce a significantly larger or more widespread postsynaptic Ca transient (Bravin et al., 1999; Morando et al., 2001). Therefore, if CFs are proximally restricted, they may produce smaller or more delimited Ca transients, making it harder for a winning CF to emerge from the competition. In Purkinje cells from juvenile mice (P15-21) that are multiply-innervated, it has been shown that activation of the stronger CF (presumably that destined to "win") produces a dendritic Ca transient that is widespread, whereas activation of a weaker CF (the presumed "loser") results in a proximally restricted Ca transient (Hashimoto and Kano, 2003). In the future, it will be interesting to determine whether sulcus Purkinje cells with proximally restricted CF innervation have $\mathrm{Ca}$ transients that are more delimited than those of bank Purkinje cells. Furthermore, it will be interesting to determine whether proximally restricted and unrestricted CFs are equipotent for triggering long-term synaptic depression of parallel fiber-Purkinje cell synapses that follows parallel fiber-CF pairing (Bear and Linden, 2000).

Alternatively, it may be that the proximal restriction of CFs in sulcus may reflect a compensatory mechanism to limit the extent of multiple CF innervation. The degree of multiple innervation might be even higher if the proximal restriction of CFs would not occur, because the territories of the different CFs in sulcus would overlap even more with each other in the distal areas of the molecular layer, where the Purkinje cell dendrites overlap.

What are the functional consequences of greater multiple CF innervation in the sulcus subdivision? One possibility is that there is no significant consequence at all: multiple climbing fiber innervation in the sulcus is merely a functionally neutral byproduct of building a folded cortical architecture. It is also possible, how-
2001). Thus, multiply-innervated sulcus Purkinje cells may integrate a somewhat broader degree of sensorimotor information from the inferior olive than their mono-innervated neighbors. This may have some functional benefit. In mutant mice lacking the $\gamma$ isoform of protein kinase C (PKC), many adult Purkinje cells remain multiply-innervated, and these mice have an accelerated acquisition rate for an associative eyelid conditioning task. This has been suggested to result from a more efficacious, integrated unconditioned stimulus signal conveyed by climbing fibers (Chen et al., 1995). Parallel fiber long-term synaptic depression was reported to be normal in PKC $\gamma$ null mice, but it may be that a more detailed parametric analysis would even find that it is enhanced in double CF-innervated Purkinje cells when both climbing fibers are activated together.

In sum, cortical folding in the cerebellar vermis has significant consequences for the physiological maturation and structure of climbing fiber innervation. The greater degree of multiple CF innervation and proximal restriction of the $\mathrm{CF}$ in the sulcus may indicate a specialized functional role for this morphological subdivision.

\section{References}

Andjus PR, Zhu L, Cesa R, Carulli D, Strata P (2003) A change in the pattern of activity affects the developmental regression of the Purkinje cell polyinnervation by climbing fibers in the rat cerebellum. Neuroscience 121:563-572.

Bear MF, Linden DJ (2000) The mechanisms and meaning of long-term synaptic depression. In: The synapse (Cowan WM, Südhof T, Stevens C, eds), pp 455-517. Baltimore: Johns Hopkins University.

Braitenberg V, Atwood RP (1958) Morphological observations on the cerebellar cortex. J Comp Neurol 109:1-33.

Bravin M, Rossi F, Strata P (1995) Different climbing fibres innervate separate dendritic regions of the same Purkinje cell in hypogranular cerebellum. J Comp Neurol 357:395-407.

Bravin M, Morando L, Vercelli A, Rossi F, Strata P (1999) Control of spine formation by electrical activity in the adult rat cerebellum. Proc Natl Acad Sci USA 96:1704-1709.

Chen C, Kano M, Abeliovich A, Chen L, Bao S, Kim JJ, Hashimoto K, Thompson RF, Tonegawa S (1995) Impaired motor coordination correlates with persistent multiple climbing fiber innervation in PKC gamma mutant mice. Cell 83:1233-1242.

Crépel F, Mariani J (1976) Multiple innervation of Purkinje cells by climbing fibers in the cerebellum of the weaver mutant mouse. J Neurobiol 7:579-582.

Crépel F, Mariani J, Delhaye-Bouchaud N (1976) Evidence for a multiple 
innervation of Purkinje cells by climbing fibers in the immature rat cerebellum. J Neurobiol 7:567-578.

Eccles JC, Ito M, Szentágothai J (1967) The cerebellum as a neuronal machine. New York: Springer.

Gellman R, Houk JC, Gibson AR (1983) Somatosensory properties of the inferior olive of the cat. J Comp Neurol 215:228-243.

Hashimoto K, Kano M (1998) Presynaptic origin of paired-pulse depression at climbing fibre-Purkinje cell synapses in the rat cerebellum. J Physiol (Lond) 506:391-405.

Hashimoto K, Kano M (2003) Functional differentiation of multiple climbing fiber inputs during synapse elimination in the developing cerebellum. Neuron 38:785-796.

Hashimoto K, Ichikawa R, Takechi H, Inoue Y, Aiba A, Sakimura K, Mishina M, Hashikawa T, Konnerth A, Watanabe M, Kano M (2001) Roles of glutamate receptor $\delta 2$ subunit (GluR $\delta 2)$ and metabotropic glutamate receptor subtype 1 (mGluR1) in climbing fiber synapse elimination during postnatal cerebellar development. J Neurosci 21:9701-9712.

Hawkes R (1992) Antigenic markers of cerebellar modules in the adult mouse. Biochem Soc Trans 20:391-395.

Hawkes R, Herrup K (1995) Aldolase C/zebrin II and the regionalization of the cerebellum. J Mol Neurosci 6:147-158.

Herrup K, Kuemerle B (1997) The compartmentalization of the cerebellum. Annu Rev Neurosci 20:61-90.

Ichikawa R, Miyazaki T, Kano M, Hashikawa T, Tatsumi H, Sakimura K, Mishina M, Inoue Y, Watanabe M (2002) Distal extension of climbing fiber territory and multiple innervation caused by aberrant wiring to adjacent spiny branchlets in cerebellar Purkinje cells lacking glutamate receptor $\delta 2$. J Neurosci 22:8487-8503.

Ito M (1984) The cerebellum and neural control. New York: Raven.

Kano M, Hashimoto K, Chen C, Abeliovich A, Aiba A, Kurihara H, Watanabe M, Inoue Y, Tonegawa S (1995) Impaired synapse elimination during cerebellar development in PKC gamma mutant mice. Cell 83:1223-1231.

Kano M, Hashimoto K, Kurihara H, Watanabe M, Inoue Y, Aiba A, Tonegawa S (1997) Persistent multiple climbing fiber innervation of cerebellar Purkinje cells in mice lacking mGluR1. Neuron 18:71-79.

Kano M, Hashimoto K, Watanabe M, Kurihara H, Offermanns S, Jiang H, Wu Y, Jun K, Shin HS, Inoue Y, Simon MI, Wu D (1998) Phospholipase cbeta 4 is specifically involved in climbing fiber synapse elimination in the developing cerebellum. Proc Natl Acad Sci USA 95:15724-15729.

Kreitzer AC, Gee KR, Archer EA, Regehr WG (2000) Monitoring presynaptic calcium dynamics in projection fibers by in vivo loading of a novel calcium indicator. Neuron 27:25-32.

Kurihara H, Hashimoto K, Kano M, Takayama C, Sakimura K, Mishina M, Inoue Y, Watanabe M (1997) Impaired parallel fiber $\rightarrow$ Purkinje cell synapse stabilization during cerebellar development of mutant mice lacking the glutamate receptor $\delta 2$ subunit. J Neurosci 17:9613-9623.

Levenes C, Daniel H, Jaillard D, Conquet F, Crépel F (1997) Incomplete regression of multiple climbing fiber innervation of cerebellar Purkinje cells in mGluR1 mutant mice. NeuroReport 8:571-574.

Lohof AM, Delhaye-Bouchaud N, Mariani J (1996) Synapse elimination in the central nervous system: functional significance and cellular mechanisms. Rev Neurosci 7:85-101.

Mariani J, Changeux JP (1980) Multiple innervation of Purkinje cells by climbing fibers in the cerebellum of the adult staggerer mutant mouse. J Neurobiol 11:41-50.

Mariani J, Crépel F, Mikoshiba K, Changeux JP, Sotelo C (1977) Anatomical, physiological and biochemical studies of the cerebellum from Reeler mutant mouse. Philos Trans R Soc Lond B Biol Sci 281:1-28.

Morando L, Cesa R, Rasetti R, Harvey R, Strata P (2001) Role of glutamate delta-2 receptors in activity-dependent competition between heterologous afferent fibers. Proc Natl Acad Sci USA 98:9954-9959.

Oberdick J, Baader SL, Schilling K (1998) From zebra stripes to postal zones: deciphering patterns of gene expression in the cerebellum. Trends Neurosci 21:383-390.

Offermanns S, Hashimoto K, Watanabe M, Sun W, Kurihara H, Thompson RF, Inoue Y, Kano M, Simon MI (1997) Impaired motor coordination and persistent multiple climbing fiber innervation of cerebellar Purkinje cells in mice lacking Galphaq. Proc Natl Acad Sci USA 94:14089-14094.

Oscarsson O (1969) The sagittal organization of the cerebellar anterior lobe as revealed by the projection patterns of the climbing fiber system. In: Neurobiology of cerebellar evolution and development (Llinás R, ed), pp 525-537. Chicago: American Medical Association.

Schild RF (1970) On the inferior olive of the albino rat. J Comp Neurol 140:255-260.

Silver RA, Momiyama A, Cull-Candy SG (1998) Locus of frequencydependent depression identified with multiple-probability fluctuation analysis at rat climbing fibre-Purkinje cell synapses. J Physiol (Lond) 510:881-902.

Strata P, Rossi F (1998) Plasticity of the olivocerebellar pathway. Trends Neurosci 21:407-413.

Sugihara I, Wu HS, Shinoda Y (2001) The entire trajectories of single olivocerebellar axons in the cerebellar cortex and their contribution to cerebellar compartmentalization. J Neurosci 21:7715-7723.

Voogd J (1969) The importance of fiber connections in the comparative anatomy of the mammalian cerebellum. In: Neurobiology of cerebellar evolution and development (Llinás R, ed), pp 493-514. Chicago: American Medical Association.

Welker WI (1990) The significance of foliation and fissuration of cerebellar cortex. The cerebellar folium as a fundamental unit of sensorimotor integration. Arch Ital Biol 128:87-109.

Zagrebelsky M, Rossi F (1999) Postnatal development and adult organization of the olivocerebellar projection map in the hypogranular cerebellum of the rat. J Comp Neurol 407:527-542. 